\title{
Sensitivity of Permafrost Adjacent to Bored Pile in Wetland Tundra During Concrete Hydration Heating
}

\author{
Ziying Liu ${ }^{1}$, Tianlai Yu ${ }^{1}{ }^{\text {, }}$, Lipeng Gu ${ }^{1}$, Ning $\operatorname{Yan}^{1}$, Hongxiang Zhang ${ }^{1}$, Zhihai Piao ${ }^{2}$ \\ ${ }^{1}$ College of Civil Engineering, Northeast Forestry University, Harbin, China \\ ${ }^{2}$ Research and Development Center, Longjian Road and Bridge Co., LTD, Harbin, China

\section{Email address:} \\ nefuliuziying@163.com (Ziying Liu), tianlaiyu@126.com (Tianlai Yu),glp8012@126.com (Lipeng Gu), \\ Yn19940610@126.com (Ning Yan), ldzhxldzhx@163.com (Hongxiang Zhang), longiianpzh@163.com (Zhihai Piao) \\ ${ }^{*}$ Corresponding author
}

\section{To cite this article:}

Ziying Liu, Tianlai Yu, Lipeng Gu, Ning Yan, Hongxiang Zhang, Zhihai Piao. Sensitivity of Permafrost Adjacent to Bored Pile in Wetland Tundra During Concrete Hydration Heating. American Journal of Civil Engineering. Vol. 8, No. 2, 2020, pp. $37-47$.

doi: $10.11648 /$ j.ajce.20200802.13

Received: May 1, 2020; Accepted: May 11, 2020; Published: May 18, 2020

\begin{abstract}
The permafrost in wetland area is very sensitive to temperature change due to its special geological conditions. By observing the temperature data of the pile-soil junction of the bored concrete pile, as well as measuring the geotechnical parameters and thermophysical parameters of the soil around the pile, it statistically analyzes the significant correlation factors related to the time when the temperature of the pile-soil junction rises to the peak, including the dry density and liquid index of the frozen soil. The formula for calculating peak time is summarized and the fitting effect is compared. The results show that peak time is positively correlated with dry density and obeys cubic curve. It is negatively correlated with the liquid index and follows the growth function curve. The peak time was not significantly correlated with the buried depth of the temperature sensor, peak temperature corresponding to the peak time, natural ground temperature, original temperature of pile wall, soil thermal conductivity, volume heat capacity, natural moisture content and plasticity index of frozen soil. The influence of concrete ratio on peak time is significant, and its correction coefficient follows S-shaped curve.
\end{abstract}

Keywords: Wetland Permafrost Area, Temperature Sensitivity, Concrete Hydration Heating, Peak Time, Dry Density, Liquidity Index

\section{Introduction}

With the global warming, the permafrost problem in cold regions is attracting more and more international attention. Surface temperatures have been measured by 575 boreholes in Russia, northern Europe and North America In the northern hemisphere [1-3]. China's permafrost area is about $2.15 \times 106 \mathrm{~km}^{2}$ [4], accounting for about $21.5 \%$ of China's land area, ranking the third in the world [5]. The high-latitude permafrost is distributed in the greater and lesser Khingan Mountains in northeast China, which is located in the southern margin of the permafrost region of Eurasia. The area is about $3.9 \times 105 \mathrm{~m}^{2}$. Permafrost soils contain enormous amounts of organic carbon, which could act as a positive feedback to global climate change [6-8]. The temperature sensitivity of decomposition of the enormous global stocks of soil organic matter has recently received considerable interest. In wetlands where anaerobic conditions often persist, especially in wetland tundra and peatlands, decomposition process is much slower than that of terrestrial mineral soils. In permafrost soils, organic matter may be buried deep in the soil by cryogenic perturbation. Thus, wetlands, peatlands and permafrost soils generally have higher carbon densities than upland soil minerals [8]. Moreover, permafrost soils and a large fraction of peatland soils occur at high latitudes, where warming is expected to be greatest, and, indeed, has already begun [9-10]. Even small permafrost temperature changes and anthropogenic thermal disturbances can have a significant impact on carbon sink storage and migration. It 
is necessary to explore the thermal law of high-latitude wetland permafrost and study the sensitive factors of soil temperature rise. It provides a theoretical basis for understanding the change rules of carbon sink stored in the soil of wetland permafrost.

Wetlandsare widely distributed in the greater hinggan mountains, with a total area of 3,935 hectares. According to the investigation results of the main diseases in the foundation of the existing railways, highways and bridges in the permafrost region of northeast China and the Siberian bea railway in Russia, the diseases in the wetland and swamp area account for $60-70 \%$ of the total diseases, which seriously affect the normal operation of traffic and greatly increase the operation and maintenance expenditure of the foundation [11-12]. Pile foundation is a common foundation form in engineering construction. most pile foundations in China adopt bored piles, since the construction method of on-site pouring is adopted, the hydration and heat release of concrete pile will cause thermal disturbance to the permafrost around the pile. Especially for pile foundation in high latitude wetland permafrost area, the thermal disturbance rule of concrete hydration heat rising on permafrost around pile is more complex. Therefore, revealing the sensitive factors and influence rule of concrete hydration heat rising on permafrost around pile has important practical significance for improving engineering design method and construction technology.

The construction of Qinghai-Tibet highway and railway in China started the observation and research on the temperature field of bridge pile foundation, and many valuable research results were formed, which provided certain reference for the research in the permafrost area of high latitude [13-17]. In addition, The construction of the China-Russia crude oil pipeline project has promoted the study of the influence of steel pipeline heating on the shallow permafrost along the pipeline and predicted the development model of permafrost in this area [18-20]. The corrosion of steels buried in marshes was studied during the rising temperature process [21]. It provides theoretical and data support for permafrost thermal disturbance caused by concrete pile foundation.

It is necessary to monitor the temperature rise process in real time with the temperature monitoring system for the pile-soil interface, collect the temperature change data of the high-latitude wetland permafrost area, and summarize the influence law and sensitive factors of frozen soil adjacent to the concrete pile during concrete hydration heating. It not only can provide the reference for the design of pile foundation in permafrost regions, cooling protection measures and implementation of operation management, but also but also for Mohe and its adjacent county Tahe in the same latitude. It is also of great significance to the production and construction of Russia's east baikal region, amur river region and other high-latitude wetland tundra regions (Figure 1).

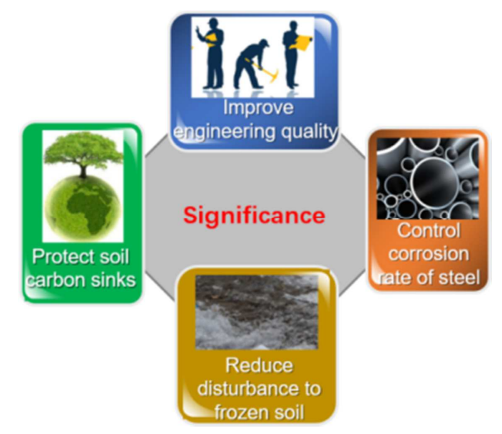

Figure 1. Significance of Project Research.

\section{Methods}

\subsection{An Overview of the Test Site}

The test site is Mohe county, Heilongjiang province, which is located at the southeast edge of the permafrost region of Eurasia, the northernmost part of China and the border of China and Russia (Figure 2). $121^{\circ} 07^{\prime} \sim 124^{\circ} 20^{\prime} \mathrm{E}, 52^{\circ} 10^{\prime} \sim$ $53^{\circ} 33^{\prime} \mathrm{N}$, average altitude $550 \mathrm{~m}$ [22]. There are abundant wetland resources due to the developed water system, the total area is up to 3,935 hectares. There is a continuous permafrost, thickness of $50 \sim 100 \mathrm{~m}$ [23]. Annual average temperature is about $-5.5^{\circ} \mathrm{C}$. The lowest temperature ever recorded is $-52.3^{\circ} \mathrm{C}$ and the highest is $38.9^{\circ} \mathrm{C}$. The average annual precipitation is $460.8 \mathrm{~mm}$, and the average annual ice period was 7 months [24]. Over the past 50 years, there is a clear warming trend in Mohe because the temperature will rise by $0.357^{\circ} \mathrm{C}$ every ten years [25]. The distribution of soil layers in the two test sites selected in this study is shown in Figure 3.

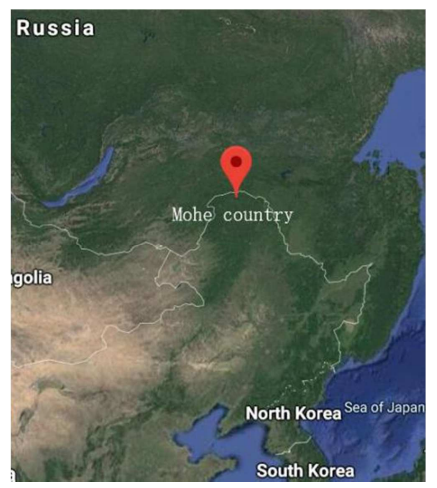

(a)

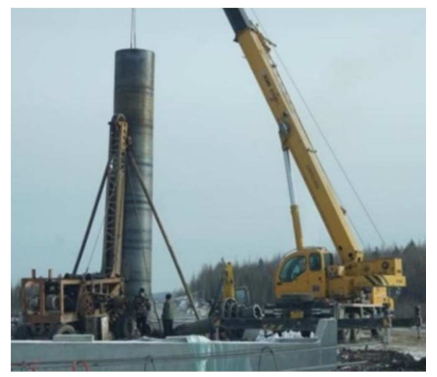

(b)

Figure 2. Geo-Localization of the Test Sites. (a) Mohe country located on the border between China and Russia, (b) Construction view of bored pile. 


\begin{tabular}{|c|c|c|c|}
\hline $\begin{array}{c}\text { sol byer } \\
\text { dstrbution }\end{array}$ & $\begin{array}{l}\text { depth form } \\
\text { he earth's } \\
\text { surfiteco[m] }\end{array}$ & $\begin{array}{l}\text { name of } \\
501 \text { tare }\end{array}$ & poe of permatrosit \\
\hline & 0.40 & humus & \\
\hline & 4.80 & camulasol & sclbearing loe \\
\hline & 6.00 & mudky soil & scitbearing ice \\
\hline vililili & 7.50 & sity clay & frezen soll filled wth 108 \\
\hline & 8.00 & round giral & frozen soli containing lats of ice \\
\hline 1 & 8.40 & sthy aley & frozen soilfiled with ice \\
\hline \% & 9.00 & round grawel & frozen soll corta'hing lots of lace \\
\hline 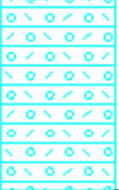 & 11,50 & $\begin{array}{c}\text { highty } \\
\text { wadterod } \\
\text { uf }\end{array}$ & frozen sol with lese icos \\
\hline
\end{tabular}

(a)

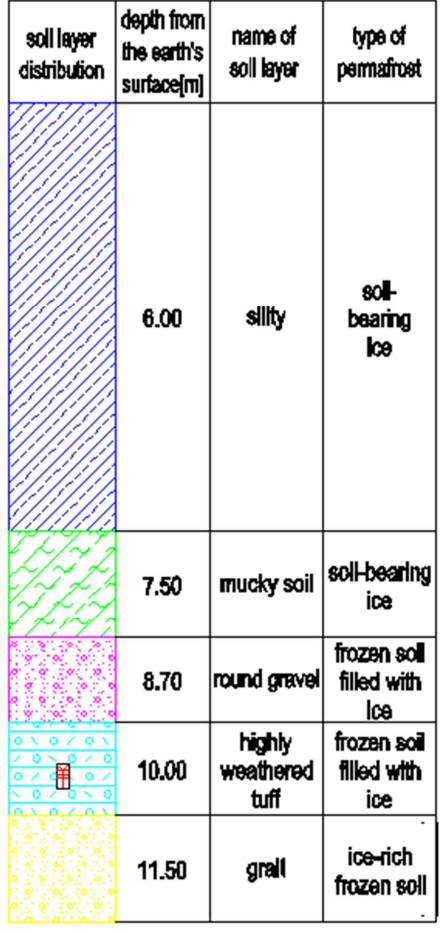

(b)

Figure 3. Distribution of Soil Layers at Different Test Sites: (a) Test Site No. 1; (b) Test Site No. 2.

Table 1. Parameters of test piles.

\begin{tabular}{lllll}
\hline Test Site & Pile Diameter $[\mathbf{m}]$ & Pile Length $[\mathrm{m}]$ & $\begin{array}{l}\text { Mix of Concrete (cement: coal ash: } \\
\text { sand: macadam: water) }\end{array}$ & $\begin{array}{l}\text { Proportion of Coal Ash in } \\
\text { Cementitious Material }\end{array}$ \\
\hline No. 1 & 1.4 & 11.5 & $1: 0.290: 2.762: 3.373: 0.545$ & $15.0 \%$ \\
No. 2 & 1.6 & 12.0 & $1: 0.410: 3.011: 3.673: 0.619$ & $29.1 \%$ \\
\hline
\end{tabular}

In order to accurately obtain the time data of the temperature rising to the maximum value of the bored pile after pouring concrete, one test pile was poured into each test site. Test pile 1 is made of conventional mixed concrete and single protecting tube. As for test pile 2, the concrete with low hydration heat mix ratio and double sheathing tube are adopted, and polyurethane foam is filled in the two-layer sheathing tube as thermal insulation material. The parameters of the two test piles are shown in Table 1.

\subsection{Composition and Layout of Temperature Monitoring System}

The temperature monitoring system is composed of temperature sensor, data cable, data acquisition and processing system and wireless transmitting system (Figure 4). The temperature sensor is a resistive temperature sensing element DS18B2. Temperature acquisition range is $-55 \sim+125^{\circ} \mathrm{C}$, Precision is $\pm 0.02^{\circ} \mathrm{C}$. The system is powered by batteries in winter and solar in summer. The device can monitor and read the temperature data of temperature measuring point at any time for a long time, and arbitrarily set the step and frequency of data reading, data storage and transmission, so as to realize wireless long-distance data transmission.

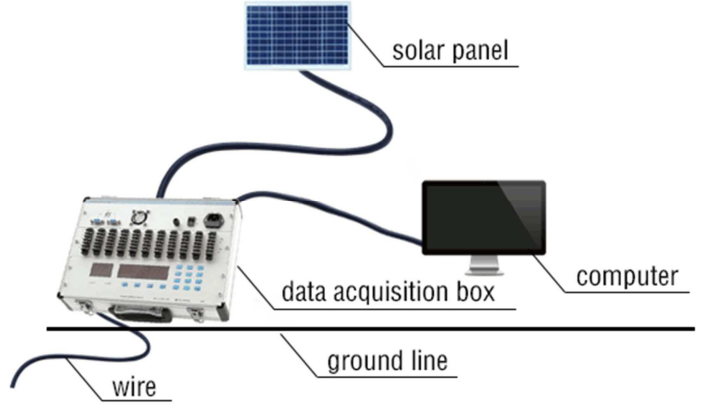

(a)

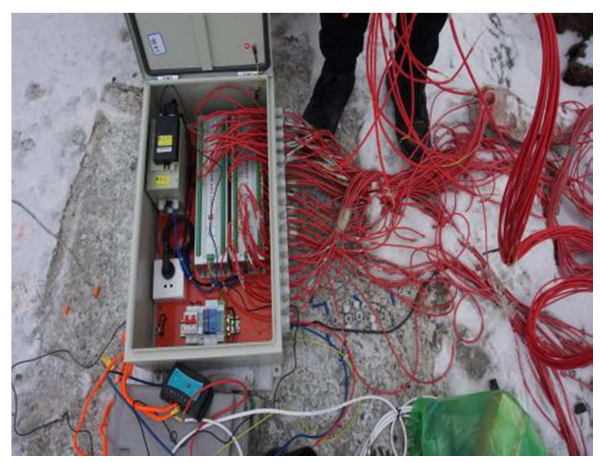

(b) 


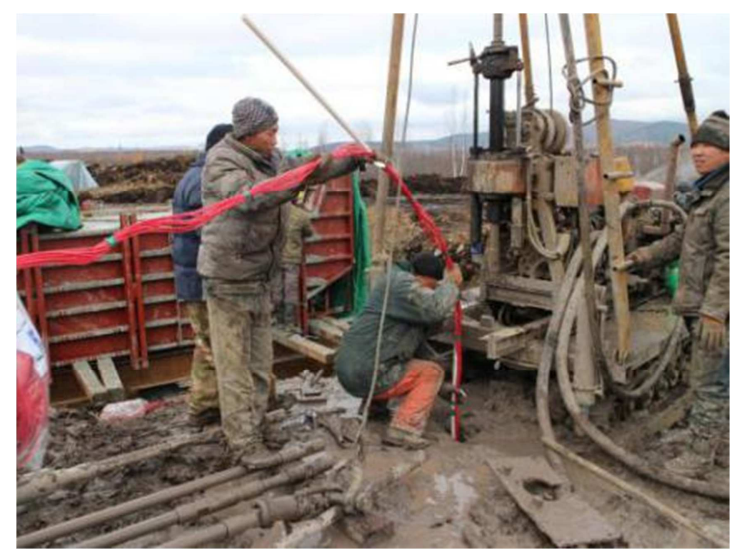

(c)

Figure 4. Temperature data sampling and transmission system: (a) Schematic diagram of temperature monitoring system; (b) Internal connection of data acquisition box; (c) View of laying the temperature measuring wire.

An intelligent temperature monitoring system was installed at the pile wall of each test pile and 3 meters away from the pile wall. A set of temperature sensors located at the pile wall were used to dynamically monitor the heating process of pile foundation from the beginning of concrete filling to the maximum temperature, and then analyzed its heating law. Another set of temperature sensors, located 3 meters away from the pile wall, was used to monitor the original ground temperature. According to the length of the concrete pile, each temperature measuring lines was composed of 13-14 temperature sensors in parallel. In order to place temperature sensors in each soil layer as far as possible, the distance between adjacent sensors was $20-130 \mathrm{~cm}$. The embedding depth of each temperature sensor in each group of temperature measuring lines was the same. The layout of the plane and elevation of the temperature observation system is shown in Figure 5, Figure 8 (a) and (c) respectively.

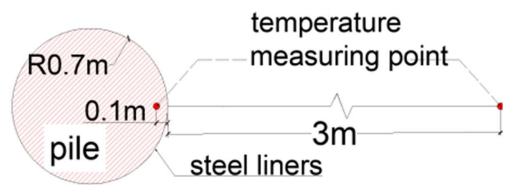

Figure 5. Layout of plane temperature monitoring system.

\subsection{Determination of Geotechnical Parameters and Thermophysical Parameters}

In order to study the influence of soil parameters on the temperature of pile-soil junction, laboratory geotechnical tests were carried out, and the soil geotechnical parameters and thermo-physical parameters were measured respectively. Geotechnical parameters included moisture content, dry density, liquid limit and plastic limit. Thermophysical parameters of soil included thermal conductivity and volume heat capacity. The natural undisturbed permafrost around the pile collected in the field was measured in the laboratory in accordance with the geotechnical test procedures [26]. The test method used for moisture content measurement was the combined measurement of frozen soil density. Dry density was measured by the ring knife method of frozen soil density after the natural density has been determined by the combined method of frozen soil density. The thermal conductivity and volume heat capacity were measured by ISOMET Model 2104 heat transfer analyzer made in Denmark. The data of thermal conductivity are all in the state of soil melting because a large amount of heat of hydration is released in the pouring process of concrete piles, and the permafrost temperature is found to be above the melting temperature through monitoring. The test equipment is shown in Figure 6. One soil sample was selected for each soil layer for geotechnical test. The results are shown in Table 2.

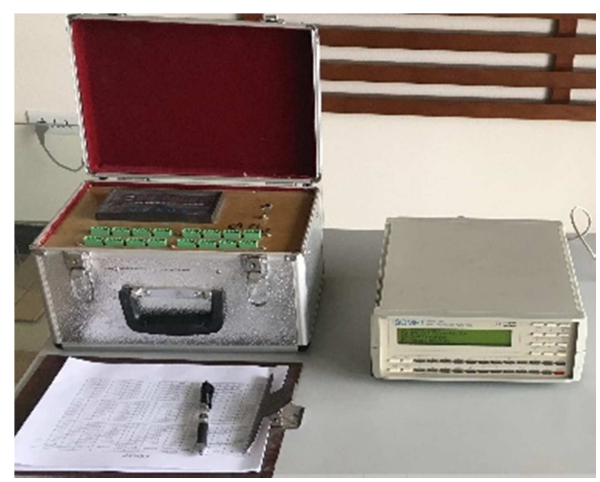

(a)

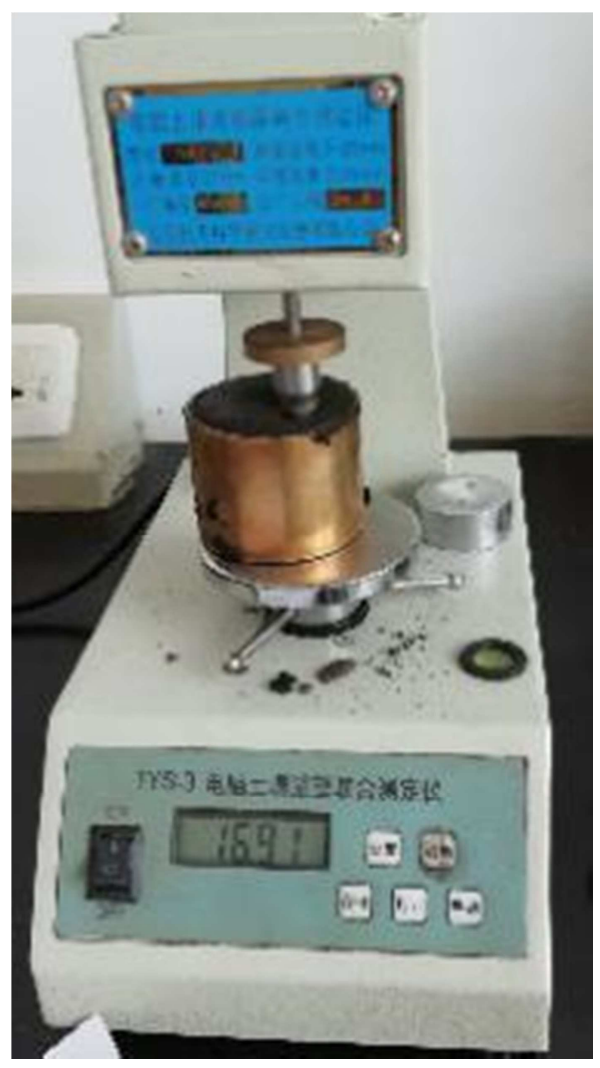

(b)

Figure 6. Geotechnical testing instruments: (a) ISOMET Model 2104 heat transfer analyzer; (b) Combined soil liquid - plastic limit tester. 
Table 2. Geotechnical parameters and thermophysical parameters of each soil layer adjacent to test pile 1.

\begin{tabular}{|c|c|c|c|c|c|c|c|}
\hline $\begin{array}{l}\text { No. of Soil } \\
\text { Layers }\end{array}$ & Depth [m] & $\begin{array}{l}\text { Moisture } \\
\text { Content [\%] }\end{array}$ & $\begin{array}{l}\text { Dry Density } \\
{\left[\mathrm{g} / \mathrm{cm}^{3}\right]}\end{array}$ & $\begin{array}{l}\text { Liquidit } \\
\text { y Index }\end{array}$ & $\begin{array}{l}\text { Plasticity } \\
\text { Index }\end{array}$ & $\begin{array}{l}\text { Thermal Conductivity } \\
{[\mathrm{W} / \mathrm{M} \cdot \mathrm{K}]}\end{array}$ & $\begin{array}{l}\text { Volumetric Heat } \\
\text { Capacity }\left[10^{6} \mathrm{~J} / \mathrm{M}^{3} \cdot \mathrm{K}\right]\end{array}$ \\
\hline 1 & 0.4 & 69.7 & 0.6 & 0.6 & 43.4 & 0.2 & 1.4 \\
\hline 2 & 3.8 & 282.5 & 0.3 & 6.0 & 39.6 & 3.0 & 1.5 \\
\hline 3 & 5.5 & 98.1 & 1.0 & 3.1 & 22.0 & 0.6 & 1.8 \\
\hline 4 & 7.0 & 36.4 & 1.4 & 1.8 & 11.1 & 1.1 & 2.1 \\
\hline 5 & 8.0 & 18.7 & 2.2 & 0.6 & 6.7 & 1.1 & 1.6 \\
\hline 6 & 8.3 & 29.9 & 2.1 & 4.4 & 3.4 & 1.2 & 2.1 \\
\hline 7 & 9.0 & 16.3 & 2.2 & 0.2 & 1.2 & 1.1 & 1.6 \\
\hline 8 & 10.0 & 10.7 & 2.2 & -0.3 & 22.1 & 3.8 & 1.6 \\
\hline
\end{tabular}

\section{Results}

\subsection{Temperature - Time Variation of Pile Wall at Different Depths}

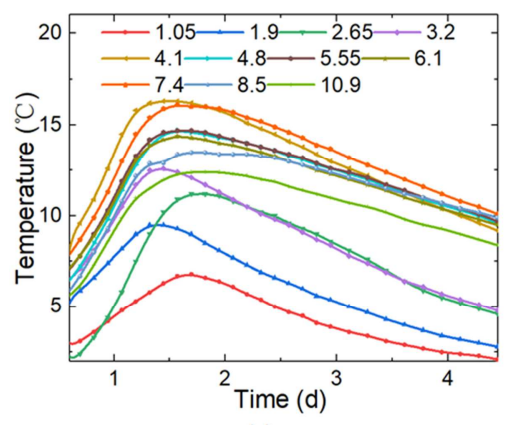

(a)

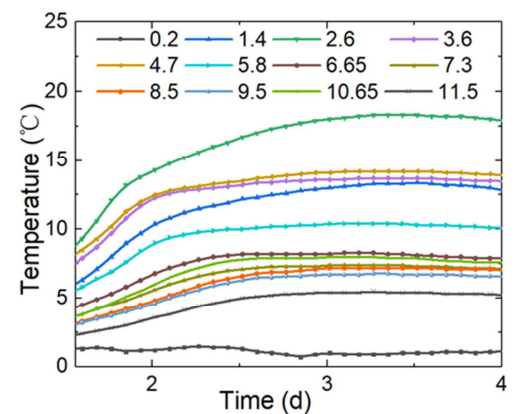

(b)

Figure 7. Relationship between pile wall temperature and concrete casting time at different depths: (a) Test Site No. 1; (b) Test Site No. 2.

Test pile No. 1 and test pile No. 2 are located in two test sites respectively. After concrete pouring is completed, the temperature change rules of each measurement point of pile wall with time are shown in Figure 7 (a) and 7 (b). The Figure in the legend represents the depth of the temperature measuring point from the earth's surface. By comparing Figure 7 (a) and 7 (b), it can be seen that the temperature variation trend of the two test piles is not similar, but the corresponding time when the peak temperature is reached has certain regularity. After concrete is poured, the temperature at each depth measurement point starts to rise slowly under the action of concrete hydration and heat release, and then gradually descend or level off after the temperature rises to the peak. The peak time of pile wall temperature at different depth measuring points is different. In addition, there is a difference between the peak time of each measuring point of test pile No. 1 and that of test pile No. 2. The peak time of test pile No. 1 appears between the 30th and 42nd hours, while that of test pile No. 2 appears between the 72th and 80th hours. The two test piles are also at different peak temperature, the peak temperature of test pile No. 1 is between 6 to $16^{\circ} \mathrm{C}$, and the peak temperature of test pile No. 2 is up to $3-18^{\circ} \mathrm{C}$. For the test pile No. 1 and No. 2, no temperature peak appears at the depth of 0.2 meters, and the temperature changes are disorderly. There is a peak time and a peak temperature at the deep temperature measuring point, but the peak time lags significantly behind the soil layers of test site No. 1 and the peak temperature is significantly lower than that of the soil layers of test site No. 1.

It is worth noting that, considering that the time of the peak after concrete pouring is only tens of hours, in order to study the law of the peak time more accurately, the time difference in the process of concrete pouring should also be taken into account. The concreting time of test pile 1 was from 11:20 am to 12: 45 PM on October 31, 2017, and lasted for 1.42 hours. Test pile 2 started at 12: 38 PM on October 22, 2017 and ended at 14: 00 $\mathrm{PM}$, lasting 1.37 hours. It is assumed that the concrete is poured at a constant speed, the time of concrete pouring to the positions of various temperature sensors is shown in Figure 8 (b) and 8 (d). The data in Figure 8 is the exact time of the temperature peak at different depths after calculation, and the casting time difference has been taken into account.

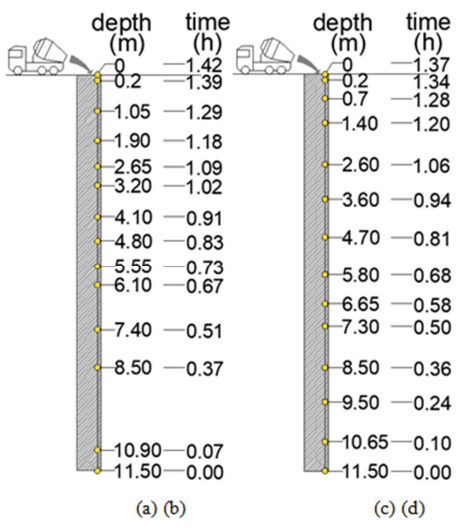

Figure 8. Elevation layout of temperature monitoring system for test pile No. land test pile No. 2: (a) Location of temperature sensor at test pile No. 1; (b) The time taken for concrete to be poured to the measuring point at test pile No. 1; (c) Location of temperature sensor at test pile No. 2; (d) The time taken for concrete to be poured to the measuring point at test pile No. 2. 


\subsection{Correlation Analysis}

In addition to the measured geotechnical parameters and thermophysical parameters, the relevant temperature parameters and the depth of the temperature sensor are also taken into account in this study. The measured temperature parameters mainly include the original ground temperature, the peak temperature of each soil layer at the pile wall, and the initial temperature of the pile wall. Original ground temperature data are derived from the measured temperature at a radial distance of $3 \mathrm{~m}$ from the pile wall. Relevant temperature parameters are shown in Table 3.

Table 3. Related temperature parameters.

\begin{tabular}{llll}
\hline Peak Time [h] & Depth of Measuring Point $[\mathbf{m}]$ & $\begin{array}{l}\text { Peak temperature } \\
{\left[{ }^{\circ} \mathbf{C}\right]}\end{array}$ & $\begin{array}{l}\text { Natural Ground Temperature } \\
{\left[{ }^{\circ} \mathbf{C}\right]}\end{array}$ \\
\hline 39.4 & 1.05 & 6.8 & -0.9 \\
30.5 & 1.9 & 9.5 & -1.3 \\
39.6 & 2.65 & 11.2 & -1.3 \\
33.6 & 3.2 & 12.6 & -1.9 \\
33.8 & 4.1 & 16.3 & -0.4 \\
36.8 & 4.8 & 14.7 & -2 \\
36.9 & 5.55 & 14.7 & -2 \\
37.0 & 6.1 & 14.4 & -2.4 \\
37.2 & 7.4 & 16.1 & -2.2 \\
40.3 & 8.5 & 13.5 & -2.7 \\
40.6 & 10.9 & 12.4 & -2.6 \\
37.7 & 12 & 11.4 & -3 \\
40.7 & 13.1 & 7.4 & -3 \\
\hline
\end{tabular}

Geotechnical parameters (Table 2) and related temperature parameters of pile and soil (Table 3 ) were analyzed with SPSS software. Since there is no temperature peak in humus soil, it is not included in the correlation statistics. The results of correlation analysis are shown in table 4.

Table 4. Correlation analysis results.

\begin{tabular}{ll}
\hline Parameter & Pearson Correlation \\
\hline Depth of Measuring Point & 0.538 \\
Peak temperature & -0.233 \\
Natural Ground Temperature & -0.487 \\
Initial Temperature of Pile Wall & 0.324 \\
Moisture Content & -0.542 \\
Dry Density & $0.599^{*}$ \\
Liquidity Index & $-0.576^{*}$ \\
Plasticity Index & -0.487 \\
Thermal Conductivity & -0.176 \\
Volumetric Heat Capacity & 0.108 \\
\hline
\end{tabular}

*. At the level of 0.05 , the correlation was significant.

It can be seen from table 4 that after pouring concrete into bored piles, the peak time at different depths is not significantly correlated with the related temperature parameters, including the embedding depth of the temperature sensor, the corresponding peak temperature at the peak time, the natural ground temperature and the original temperature of pile wall. The peak time was also not significantly correlated with soil thermal conductivity and volume heat capacity. It is not significantly correlated with the natural moisture content and plasticity index of frozen soil, but only significantly correlated with the dry density and liquid index of frozen soil at the level of 0.05 .

\subsection{Relationship Between Peak time and Dry Density}

Despite the classification of frozen soil, the actual soil quality within the scope of each soil layer is not completely uniform. Therefore, even in the same soil layer, the geotechnical parameters of undisturbed soil are relatively complex. As mentioned above, one soil sample was selected for each soil layer for geotechnical parameter test. In order to obtain more accurate data, we selected the temperature monitoring data of the nearest test soil sample for geotechnical parameters in each representative soil layer as the basis for the next calculation. The curve of the relationship between peak time and dry density was plotted as shown in Figure 9.

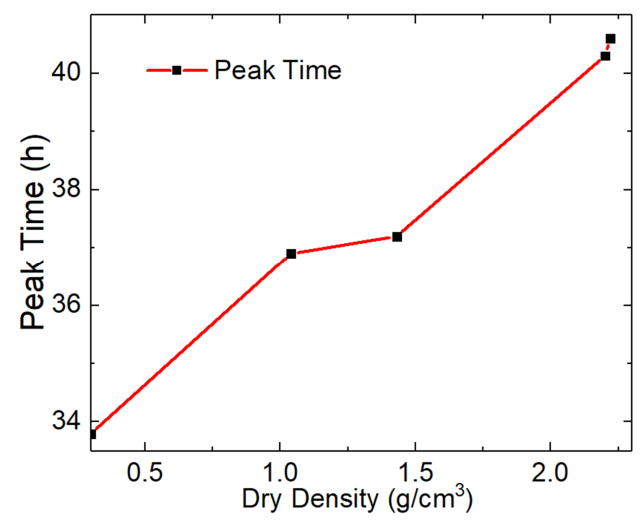

Figure 9. Relation curve between peak time and dry density of frozen soil.

The regression equation with peak time as dependent variable and dry density as independent variable is obtained by nonlinear regression method. The fitting effect of cubic model is best found by comparison. The regression equation is shown in formula 1 and analysis of variance is shown in table 5. As can be seen from the table 5, the regression effect is good.

$\mathrm{t}=\mathrm{f}\left(\gamma_{d}\right)=30.111+15.613 \gamma_{d}-12.017 \gamma_{d}^{2}+3.199 \gamma_{d}^{3}$

Where, $\mathrm{t}$ is the time when the peak temperature appears, and $\gamma_{d}$ is the dry density of frozen soil. 
Table 5. Analysis of Variance.

\begin{tabular}{llll}
\hline $\begin{array}{l}\text { Multiple Correlation } \\
\text { Coefficient } \mathbf{R}^{2}\end{array}$ & $\begin{array}{l}\text { Standard } \\
\text { Error }\end{array}$ & F Value & Significance \\
\hline 0.999 & 0.08 & 1620.627 & 0.018 \\
\hline
\end{tabular}

\subsection{Relationship Between Peak Time and Liquidity Index}

The curve of the relationship between peak time and liquidity index was plotted as shown in figure 10 .

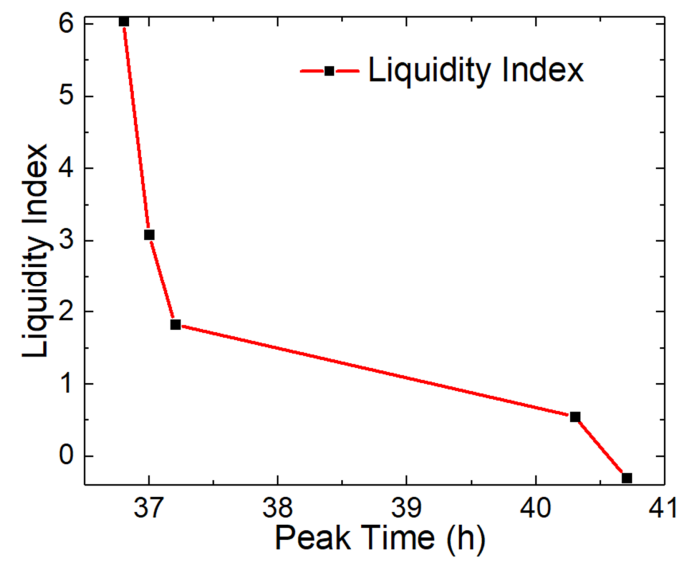

Figure 10. Relation curve between peak time and liquidity index of frozen soil.

The regression equation with peak time as dependent variable and liquidity index as independent variable is obtained by nonlinear regression method. The fitting effect of growth model is best found by comparison. The regression equation is shown in formula 2 and analysis of variance is shown in table 6. As can be seen from the table 5, the regression effect is also good.

$$
\mathrm{t}=\mathrm{f}\left(I_{L}\right)=e^{\left(3.696-0.030 \times I_{L}\right)}
$$

Where, $\mathrm{t}$ is still the time when the peak temperature appears, and $\mathrm{I}_{L}$ is the liquidity index of frozen soil.

Table 6. Analysis of Variance.

\begin{tabular}{llll}
\hline $\begin{array}{l}\text { Multiple Correlation } \\
\text { Coefficient } \mathbf{R}^{2}\end{array}$ & $\begin{array}{l}\text { Standard } \\
\text { Error }\end{array}$ & F Value & Significance \\
\hline 0.958 & 0.18 & 68.566 & 0.004 \\
\hline
\end{tabular}

\section{Finite Element Verification}

\subsection{Basic Assumptions of the Model}

Taking test pile 1 as an example, the Solidworks software is used to build the $3 \mathrm{~d}$ model at first, and then FLUENT module is used to analyze the heat transfer and heating process of concrete hydration heat on permafrost around the pile [27, 28]. Relevant assumptions of the model are as follows:

The air, soil layers and pile concrete are uniform respectively;

Pile body completely relies on the side surface for heat dissipation;

The whole pile is in complete contact with the surrounding frozen soil;
The outer wall of the soil layer is adiabatic, which is 3 meters away from the radial direction of the pile wall.

\subsection{Model Building and Mesh Generation}

According to the actual size of bored pile and the range of its influence on frozen soil temperature, a full model is established. The model of test pile 1 includes three parts: air domain, concrete, multi-layer soil around pile. The air domain model is simplified into a $10 \times 10 \times 5 \mathrm{~m}^{3}$ cuboid. Concrete model is a cylinder with a diameter of $1.4 \mathrm{~m}$ and a length of $11.5 \mathrm{~m}$. Soil model around the pile is a ring body, which extends $3 \mathrm{~m}$ radially outward from the boundary of the pile and soil. The thickness of each soil layer is the same as that shown in figure 2. Soil model at the bottom of the pile is a cylinder extending 2.5 meters vertically downward from the bottom of the concrete pile with a diameter of $7.4 \mathrm{~m}$. The size of the geometric model is shown in Figure 11.

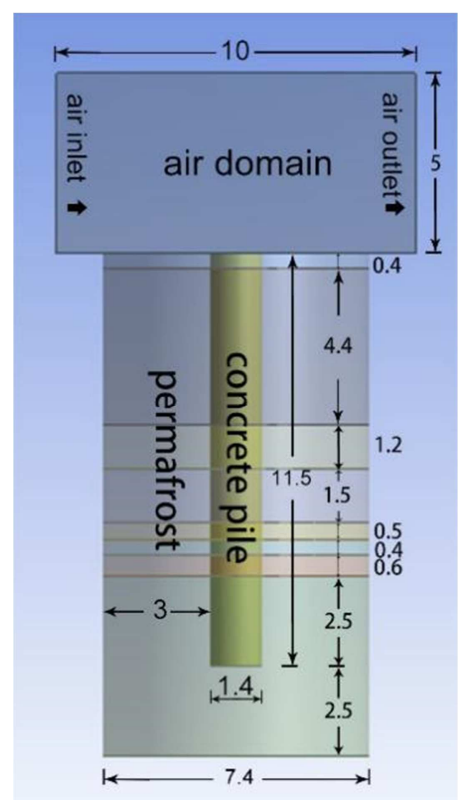

Figure 11. Geometric model (Unit: m).

The model is divided into a regular hexahedral element with an edge length of $10 \mathrm{~cm}$, and the whole model is divided into 1151,722 mesh elements. Multizone method is used to divide the air domain grid. According to the command of sweep method, the grid of concrete and soil is divided to make each node of the grid correspond to each other to ensure the best heat transfer effect. Grid generation is shown in Figure 12:

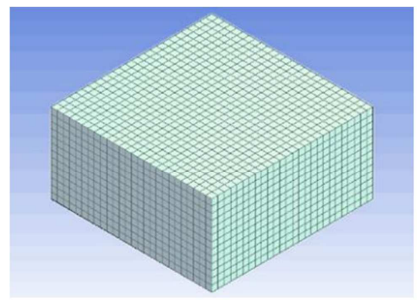

(a)

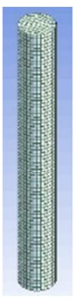

(b)

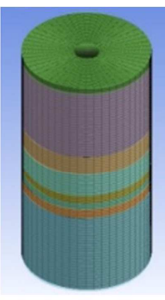

(c)
Figure 12. Grid division of the model. (a) air domain: (a) air domain; (b) concrete pile; (c) permafrost around and at the bottom of pile. 


\subsection{Boundary Conditions}

The calculated parameters of materials are as follows: the air domain model involves the convection effect between soil and air, and the factors taken into account include direct solar radiation, scattered radiation, wind speed and air temperature. The relationship between the hydration heat parameters of concrete piles and the mix ratio is shown in figure 13. The figure in the legend represents the proportion of coal ash in the cementitious material in the concrete with low hydration heat, and "conventional" represents conventional mixed concrete, not low hydration heat concrete. The geotechnical parameters are shown in table 2 .

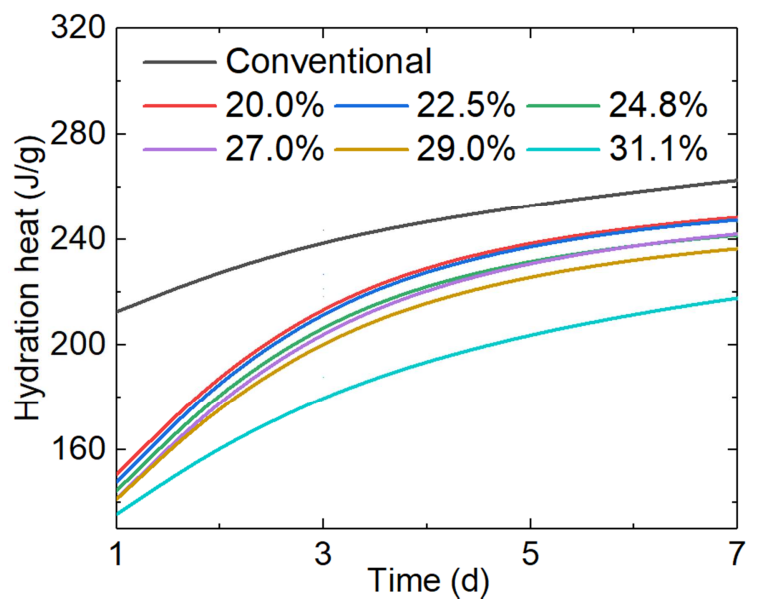

Figure 13. Relationship between the hydration heat parameters of concrete pile and the mixture ratio.

\subsection{Determine the Correction Coefficient}

As for the regression formula 4 and the concrete mixture ratio parameter of test pile 1 , the calculation equation of the time when the pile-soil junction reaches the peak temperature during the concrete hydration heating process under similar geological conditions in the high-latitude wetland permafrost area is established, as shown in equation 3 .

$$
\mathrm{t}=\mathrm{f}\left(\gamma_{d}\right) \cdot \alpha
$$

Where, $\alpha$ is the correction coefficient of different concrete mix proportion, which takes the percentage of coal ash in cementitious material as the reference index.

Taking the factors of different mix proportion of concrete as variables, the remaining parameters were fixed. The corresponding time of peak temperature was calculated by finite element model, and the calculated peak time was divided by the measured peak time of pile 1 . The results are obtained by nonlinear regression. The regression curve with the correction coefficient as the dependent variable and the percentage of coal ash in the cementing material as the independent variable is shown in figure 14. Regression equation obeys S-curve model.

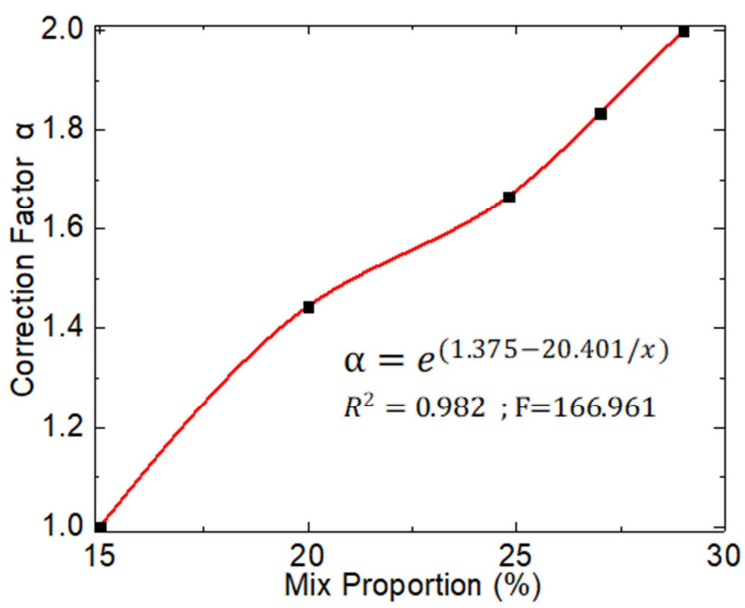

Figure 14. Regression curve of correction coefficient.

Then the modified equation is:

$$
\mathrm{t}=\left(30.111+15.613 \gamma_{d}-12.017 \gamma_{d}^{2}+3.199 \gamma_{d}^{3}\right) \cdot e^{(1.375-20.401 / x)}
$$

Where, $x$ is the percentage of coal ash in the cementitious material, $\%$. When the mixture ratio is $\geq 15 \%$, formula 7 is applicable. However, when the mixture ratio is $\leq 15 \%$, it is recommended to take a conservative value, preferably $15 \%$, as there is no sufficient data support at present.

The calculated parameters of test pile 2 (shown in table 1 and table 7) are respectively substituted into formula 7 to calculate the peak time of concrete hydration heating during the concrete pouring stage of test pile 2 . A measured value is selected for each homogeneous soil layer for checking calculation, and the checking results are shown in table 7.

Similarly, the modified regression equation with liquid limit index as the independent variable is:

$$
\mathrm{t}=\mathrm{f}\left(I_{L}\right)=e^{\left(3.696-0.030 \times I_{L}\right)} \cdot e^{(1.375-20.401 / x)}
$$

Simplify this equation to get:

$$
\mathrm{t}=\mathrm{f}\left(I_{L}\right)=e^{\left(5.071-0.030 \times I_{L}-20.401 / x\right)}
$$

\begin{tabular}{|c|c|c|c|c|c|c|c|c|c|}
\hline \multirow{2}{*}{ No. } & \multirow{2}{*}{ of Soil Layer } & \multirow{2}{*}{ Depth [m] } & \multirow{2}{*}{ Dry Density $\left[\mathrm{g} / \mathrm{cm}^{3}\right]$} & \multirow{2}{*}{ Liquidity Index } & \multicolumn{3}{|c|}{ Peak Time [h] } & \multicolumn{2}{|c|}{ Error Rate [\%] } \\
\hline & & & & & Measured & $a *$ & $\mathbf{b}^{*}$ & $a *$ & $\mathbf{b}^{*}$ \\
\hline 1 & & 3.6 & 0.6 & 4.2 & 71.3 & 71.3 & 71.0 & 0.0 & -0.5 \\
\hline 2 & & 6.65 & 1.0 & 3.8 & 72.7 & 73.7 & 71.9 & 1.4 & -1.1 \\
\hline 3 & & 8.5 & 1.8 & 2.6 & 75.9 & 75.7 & 74.6 & -0.3 & -1.6 \\
\hline 4 & & 9.5 & 1.9 & 1.4 & 77.0 & 76.3 & 77.2 & -0.9 & 0.3 \\
\hline 5 & & 11.5 & 2.0 & 0.9 & 78.3 & 78.1 & 78.5 & -0.2 & 0.3 \\
\hline
\end{tabular}

Table 7. Comparison of Calculated Value and Measured Value of Peak Temperature of Test Pile No. 2.

*. "a" and "b" are the values calculated with dry density and liquid index as independent variables respectively.

As can be seen from table 7 , the error rate is between $-1.6 \sim 1.4 \%$, which proves that the calculation results are 
reliable.

\section{Discussion}

From this study the following conclusions are drawn:

(1) When the hydration heat generated by concrete pile foundation is transferred in frozen soil, its peak time is significantly correlated with the dry density of frozen soil, which increases with the increase of dry density. The main reasons are as follows: for the soil of the same volume, the dry density is determined by the mass of soil particles. The higher the particle mass, the higher the dry density, and vice versa. According to Newton's law of gravitation, the adsorption capacity of soil particles to the liquid water around them is closely related to their own mass. For example, for peaty soil and silty soil with relatively small soil particle mass, their ability to absorb water is weak, the water film formed on the surface of soil particles is thin, and the binding force of molecular bonds is weak. During the hydration and heat release of concrete, the water in the frozen soil needs less heat in the process from combined water to free water by means of heat absorption, so the peak time is relatively short. It should be noted that, the specific surface area of soil particles is relatively large for soils with small particle sizes, which creates certain conditions for adsorbing free water between soil particles, but the mass of soil particles, namely the dry density of frozen soil, still plays a dominant role.

(2) When the hydration heat generated by concrete pile foundation is transferred in frozen soil, its peak time is significantly related to the liquid index of frozen soil, which decreases with the increase of the liquid index. The main reasons are as follows: the rate of temperature rise of frozen soil is affected by both the moisture content of frozen soil and soil type. Moreover, ice and liquid water coexist in frozen soil, the latent heat of phase change changes with the change of unfrozen water content at any time. Therefore, when the temperature of soil rises after heat absorption, the peak time is not only significantly correlated with water content, but also not only with soil type. The fluidity index is a physical index that combines soil type and water content. In the wetland tundra, all kinds of soil are almost saturated or nearly saturated. According to the viewpoint of molecular dynamics and thermodynamics, the potential of soil water in frozen soil is almost zero or close to zero. Since the soil particles have no larger surface energy to attract the capillary water and free water between the soil particles, the water hardly flows or flows very little after the endothermic melting of the ice in the frozen soil, and the soil particles will not migrate with the water flow. This is an important guarantee for the constant moisture content and stable soil structure. It is also the reason that its liquid index is almost stable. Therefore, in the wetland permafrost area, the fluidity index can not only be used to judge the soft and hard state of soil, but also be used as the main relevant index to analyze the law of frozen soil temperature.

(3) The peak time of frozen soil is not significantly correlated with two thermal physical parameters of frozen soil, namely thermal conductivity and volume heat capacity, for the following reasons: Firstly, the thermal conductivity of frozen soil is related to its mineral composition and structure The thermal conductivity of crystalline materials increases with the decrease of temperature, and that of amorphous materials decreases with the decrease of temperature. The thermal conductivity of soil and gases in water is essentially the same as that of amorphous substances. Since the soil is a heterogeneous system composed of various components, there is no uniform law of its thermal conductivity with the change of temperature [29], so there is no law of peak time. Secondly, the specific heat capacity of frozen soil is related to dry bulk density, organic matter content, mineral composition, water content and other factors. Secondly, the specific heat capacity of frozen soil is related to the dry bulk density, organic matter content, mineral composition, water content and other factors of the soil, and the composition of soil solid phase material is relatively stable, the influence of air can be ignored. Therefore, the specific heat capacity of frozen soil mainly changes with the content of ice and water in frozen soil. During the heating process of permafrost after heat absorption, the unfrozen water content keeps changing, which makes the temperature of permafrost lag behind to varying degrees. Therefore, there is no significant correlation between the peak heating time and the specific heat capacity of permafrost.

(4) The peak time formula does not apply near the surface or to ice in the frozen soil of wetlands. The closer to the surface, the greater the error. This is mainly because the closer to the surface, the more open the system is, and the more complex the influencing factors are. Firstly, environmental factors such as humus and other organic matter, solar radiation, atmospheric temperature, relative air pressure and wind speed have great interference on the heating time. Secondly, in high latitudes, the inversion layer is extremely significant, especially in winter, the inversion layer is not only thicker, but also disappears slowly. Even on a clear or breezy night, inversion layers occur when the ground cools rapidly due to radiation, causing the atmosphere close to the ground to cool. The atmospheric inversion layer absorbs a large amount of heat from frozen soil, so that the peak time of soil temperature no longer follows the formula presented in this paper. Therefore, it is not recommended to calculate the peak time for frozen soil above the standard freezing depth according to the formula in this study.

Because of abundant water source, ice interlayer is easily formed in the clay layer in the wetland tundra. Even in soils 
with large particle sizes, thin ice layers with clays still can occur. The physical properties of these ice interlayers are different from that of frozen soil, and the mechanism of water migration and movement is also different from that of conventional frozen soil. Therefore, it is not recommended to calculate such ice interlayers according to the formula in this study.

\section{Conclusions}

According to the data collected by the intelligent temperature monitoring system, the temperature at the pile-soil junction in wetland tundra presents a dynamic change process of rising and then falling under the action of the hydration heat of concrete after the bored pile is poured. For the permafrost regions with large moisture content, the temperature first rises, then stabilizes and then slowly cools down.

The peak time of temperature rise is related to the dry density and liquid index of frozen soil, but not significantly related to the buried depth of temperature sensor, peak temperature corresponding to the peak time, natural ground temperature, original temperature of pile wall, soil thermal conductivity, volume heat capacity, natural moisture content and plasticity index of frozen soil. Peak time was positively correlated with dry density, which was in line with the curve law of cubic function. It is negatively correlated with the liquid index and obeys the curve law of the growth function.

According to the measured results, under the condition of the same pile length and diameter, the peak time of the pile-soil junction of the concrete poured pile with the mixing ratio of $29 \%$ is twice as long as that of the mixing ratio of $15 \%$. The influence of concrete ratio on the peak time is significant, and its correction coefficient obeys the law of s-shaped curve.

The corresponding time of peak temperature at the pile-soil junction under different working conditions is calculated with statistical software and finite element analysis software, and the calculation equation of peak time is established. It is verified that the deviation between the calculated value and the measured value is $-1.6 \sim 1.4 \%$, indicating that the established calculation equation is accurate and reliable.

\section{Author Contributions}

Conceptualization, T. Y. and Z. L.; Methodology, T. Y. and Z. L.; Software, Z. L. and N. Y.; Validation, Z. L. and N. Y.; Investigation and experiment, L. G., Z. L., H. Z. and Z. P.; Resources, T. Y.; Data Curation, Z. L. and N. Y.; Writing and Visualization, Z. L.

\section{Funding}

This work was funded by Basic Scientific Research Operating Expenses of Central Universities (No. 2572015BB03), Longjian Road and Bridge Co., LTD. Science and Technology Project (No. LJKY004-2017).

\section{Acknowledgements}

The author would like to thank the Northeast Forestry University Forest and his supervisor for valuable suggestion to facilitate this project. We would like to thank the editor and the anonymous reviewers for their work.

\section{Conflicts of Interest}

The author declares no conflict of interest.

\section{References}

[1] Romanovsky, Vladimir E.; Smith, Sharon L.; and Christiansen, Hanne H. Permafrost Thermal State in the Polar Northern Hemisphere during the International Polar Year 2007-2009: a Synthesis. Permafrost and Periglacial Processes, 2010, 21, 106-116.

[2] Romanovsky, V. E.; Drozdov, D. S.; and Oberman, N. G.; et al. Thermal State of Permafrost in Russia. Permafrost and Periglacial Processes, 2010, 21, 136-155.

[3] Smith, S. L.; Romanovsky, V. E.; Lewkowicz, A. G.; et al. Thermal State of Permafrost in North America: A Contribution to the International Polar Year. Permafrost and Periglacial Processes 2010, 21, 117-135.

[4] Zhou You-wu; Guo Dong-xin; and Qiu Guo-qing; et al. China's Permafrost. Science Press: Beijing, China, 2000; pp. 40-41.

[5] Song Wen-yu. Numerical Simulation Of Subgrade Frozen Soil Environment And Optimization Design Of Temperature Control System. Master's Thesis. Harbin Institute of Technology, Harbin, China, 2010.

[6] Koven CD, Ringeval B, Friedlingstein P, Ciais P, Cadule P, Khvorostyanov D, et al. Permafrost carbon-climate feedbacks accelerate global warming. Proc. of the National Acad. of Sci. of U.S.A. 2011, 108, 14769-74.

[7] Kurz WA, Shaw CH, Boisvenue C, Stinson G, Metsaranta J, Leckie D, et al. Carbon in Canada's boreal forest - A synthesis. Environ. Rev. 2013, 21, 260-92.

[8] Davidson EA, Janssens IA. Temperature sensitivity of soil carbon decomposition and feedbacks to climate change. Nat. 2006; 440, 165-73.

[9] Arctic Climate Impact Assessment (ACIA). Impacts of a Warming Arctic: Arctic Climate Impact Assessment; Cambridge Univ. Press: Cambridge, UK, 2004; http://amap.no/acia/l.

[10] Chapin, F. S. III et al. Role of land-surface changes in Arctic summer warming. Science 2005, 310, 657-660.

[11] Duan Dong-ming. Study on Subgrade Engineering of Permafrost Wetland; China railway publishing house: Beijing, China, 2010; pp. 1-5.

[12] Orlando B. Andersland; Branko Ladanyi. Frozen Ground Engineering, 2nd Edition; China Architecture And Building Press: Beinjing, China, 2001; pp. 196.

[13] Shang Yun-hu, Yuan Kun, Niu Fu-jun, et al. Study on ground temperature of cast-in-place pile of bridge in permafrost regions. J. Glaciology and Geocryology 2016, 38, 1129-1135. 
[14] Fu Jin, Jiang Yu, Peng Hui, et al. Early Refreezing Law of Large-Diameter Cast-in-Place Piles in Permafrost Regions. $J$. Traffic and Transportation Eng. 2016, 16: 104-110.

[15] Shang Yun-hu, Niu Fu-jun, Liu Ming-hao, et al. Long-Term Effect of a Pile Foundation on Ground Temperatures in Permafrost Regions. Chin. J. Rock Mech. Eng. 2017, 36, 2313-2323.

[16] Wang Xu, Jiang Dai-jun, Zhao Xin-yu, et al. An Experimental Study on Refreezing Characteristics of Large-Diameter Bored Pile in Different Permafrost Areas of The Qinghai-Tibet Plateau. Chin. J. Rock Mech. Eng. 2004, 23, 4206-4211.

[17] Yu De-zhong, Cheng Pei-feng, and Ji Cheng, et al. Study of Refreezing of Bored Pile in High Latitudes and Low Elevation Patchy Permafrost Regions. J. Highway and Transportation Res. Dvpt. 2016, 33, 88-94.

[18] Chen Yan-jiang, Ding Lin, Guo Zi-chuan, et al. Impact of Climate Change in the Permafrost Regions along the Mohe-Daqing Oil Pipeline. J. Eng. Heilongjiang Univ. 2016, 7, $9-15$.

[19] Lü Lan-zhi, Jin Hui-jun, Chang Xiao-li, et al. Interannual Variations of the Air Temperature, Surface Temperature and Shallow Ground Temperature along the China-Russia Crude Oil Pipeline. J. Glaciology and Geocryology, 2010, 32, 794-801.

[20] Leng Yi-fei. Experimental Research on Physical Mechanical Properties and Numerical Analysis on Temperature Field of Permafrost of China-Russia Oil Pipeline. Doctoral Thesis. College of Construction Engineering, Jilin University, Changchun, China, 2011.
[21] Luo Peng, Wang Hong-zhi, Liu Lei, et al. corrosion study of Q235 steel in pipelinesoil of frost. Pipeline Techniq. Equip. 2015, 6, 37-39.

[22] Lu Yan; Yu Wen-bing; Guo Ming; et al. Spatiotemporal variation characteristics of land cover and land surface temperature in Mohe County, Heilongjiang Province. $J$. Glaciol. and Geocryol., 2017, 39, 1137-1149.

[23] Jin Hui-jun; Yu Qi-hao; Lü Lan-zhi; et al. Degradation of permafrost in the Xing'anling Mountains, Northeastern China. J. Permafrost and Periglacial Proc. 2007, 18, 245 -258.

[24] Chen Lin; Yu Wen-bing; Yi Xin; et al. Application of ground penetration radar to permafrost survey in Mohe County, Heilongjiang Province. J. Glaciol. Geocryol. 2015, 37, 723-730.

[25] Yu Wen-bing; Guo M; Chen L; et al. Influence of urbanization on permafrost: a case study from Mohe County, Northernmost China. Cryosph. Discuss., 2014, 8, 4327-4348.

[26] Test methods of soils for highway engineering, JTG E40-2007. Ministry of communications of the People's Republic of China.

[27] Liu Yan-feng; Gao Zheng-yang; Liang Jun-xiu. Heat Transfer; China Electric Power Press: Beijing, China, 2015; pp. 167-170.

[28] Zhang Jing-zhou. Advanced Heat Transfer; Science Press: Beijing, China, 2015; pp. 98-104.

[29] Zheng Xiu-qing; Fan Gui-sheng; Xing Shu-yan, et al. Movement of Water in Seasonally Unsaturated Freeze-thaw Soils; Geological press: Beijing, China, 2002; pp. 22-23. 